\title{
Characteristics of Undergraduate Students with Disabilities: Disability Disclosure and Academic Persistence
}

\author{
Valerie Thompson-Ebanks \\ Assistant Professor, University of Wyoming \\ Division of Social Work, University of Wyoming \\ University Avenue, Laramie \\ Michelle Jarman \\ Associate Professor, University of Wyoming \\ Wyoming Institute for Disabilities, University of Wyoming \\ University Avenue, Laramie
}

\begin{abstract}
This pilot study used a 14-question online survey to examine two key characteristics of undergraduate students with self-identified disabilities: nondisclosure/disclosure to disability services; and utilization of accommodations through disability support services. A total of 10,100 students were sent the survey and 111 were returned completed. Of the 111 completed surveys, 31 students identified as having disabilities perceived to interfere with academic performance. The most notable difference between the characteristics of students with disabilities who disclosed to disability services and those who did not disclose was the prevalence of nondisclosure among students with self-identified psychological disabilities. Recommendations for university and college administrators are included.
\end{abstract}

Key words: students with disabilities; undergraduates; college/university; disability disclosure; disability support services.

\section{INTORDUCTION}

An increase in the enrollment of college students with disabilities has been documented [1-4] This increase can be attributed to a rise in the percentage of students diagnosed with a disability [5]; increase in the number of student veterans with disabilities; and a number of new federal regulations. The federal regulations include the Americans with Disabilities Act [ADA] of 1990 and its 2008 Amendments that expanded the definition of disability; the Higher Education Act (HEA); and the post-9/11 Veterans Educational Assistance Act that expanded educational benefits for veterans [6-7].

Students are considered to have a disability if they experience functional limitations that significantly restrict one or more of life's essential activities such as walking, seeing, and learning [8]. The term nonapparent disability refers to disabilities with symptoms that are often not immediately noticeable or apparent to an observer [9]. Such disabilities may include psychological and emotional disabilities, learning disabilities, Autism Spectrum Disorders, and many medical conditions such as arthritis, cancer, diabetes, and hearing loss.

Institutions of higher education are required to serve students with disabilities by providing them with "reasonable accommodations" to allow them equal access to education $[2,10]$ as mandated by the American with Disabilities Act [11]. Reasonable accommodations may 
include: "the implementation of sign language, audio amplification devices, Braille, or magnification devices ... extended test times, permitting frequent breaks during exams, or allowing testing in a separate room" [2, p. 37]. Colleges and Universities typically offer support for students with disabilities (SWDs) through a designated office that provides various accommodations and related services, often called the disability support services (DSS) office. Services for college students with disabilities may include individualized accommodation plans, specialized academic advising, transition coaching, assistive technology, referrals to campus and community services, and other disability-related services such as advocacy and study skills workshops.

Colleges and universities are only legally obligated to provide accommodations if students formally disclose their disability to the institution with supportive documentation that indicates that an accommodation is warranted. However, as several scholars [12-16] indicate, simply fulfilling legal mandates may be inadequate in meeting the needs of college students with disabilities.

Utilization of support services by SWDs, namely, assistive technology and other forms of academic accommodations is found to be associated with persistence and graduation rates among students with disabilities [1,17]. Conversely, Culligan [1] found that SWDs who did not use any support services were at risk of earning the lowest mean number of college credits. Whether a student actually decides to disclose his or her disability is one barrier to utilization of disabilities services and accommodations by students with disabilities. Given the importance of disability disclosure among those students with disabilities who require accommodation, it was surprising that these authors were unable to find any literature that examined the characteristics of students with disabilities who choose to disclose and those who choose not to disclose.

In this current study, a 14-question online survey was administered to 10,100 college students; 111 students completed and returned the survey. Those with self-identified disabilities were identified. Characteristics of this subset of SWDs are presented with particular attention given to whether the participant disclosed their disability to disability support services (DSS) and whether the student accessed services from DSS. This pilot study aimed to answer two primary questions:

1. What are the characteristics of students who identify as having a disability and make the decision to disclose their disability to DSS compared to students with self-identified disabilities and make the decision not to disclose their disability to DSS?

2. What are the characteristics of students who disclose and utilize DSS services compared to those who disclose and choose not to utilize DSS?

\section{LITERATURE REVIEW}

A brief review of the literature pertaining to disability disclosure and utilization of services among SWDs in higher education is provided. Factors SWDs consider when deciding whether or not to disclose their disability are mentioned.

\section{Disclosure of Disabilities by Students with Disabilities}

Several research studies have been published that address the issue of disclosure by SWDs. Disability disclosure is defined as the personal decision to tell an institution about one's disability [18]. It is important to know that only students with a diagnosed disability evidenced by appropriate documentation are eligible to receive disability services on college and university campuses. Hudson [19] reported that students who did not disclose their 
disabilities, and thus did not receive formal disability services, were three and a half times more likely to not graduate in six years than those students who formally disclosed their disability to the institution and receive services. On the other hand, Herbert et al. [13] examined the graduation and persistence rates of college students who sought disability services over a 10-year period (1996-2006) at a mid-Atlantic university and found that the graduation rate of students with disabilities who received services was very similar to those who sought disability services but did not receive them: $66.5 \%$ and $66.1 \%$ respectively. The authors reported three reasons that $54 \%$ of students who sought disability services did not receive services: student did not provide any documentation to verify the existence of a disability; student did not follow proper guidelines or provide appropriate documentation to establish the existence of a disability; and, student provided documentation of disability, but the disability was not considered eligible under the Americans with Disabilities Act (ADA) to warrant a reasonable accommodation after review by the disability office staff.

Students with disabilities may not formally disclose their disability to DSS or informally disclose to their professors. Kranke et al. [2] identified three pathways to a disability disclosure decision: (a) students disclose their disability immediately in order to raise professor awareness; (b) students delay disclosure until their disability limits their functioning; and (c) students do not disclose at all. Factors associated with choosing to disclose their disability in college include: feelings of stigmatization; wishing to take on a new persona from that in high school; fearing negative perceptions of peers and faculty; fearing marginalization, discrimination, and being treated differently; believing that there is a chilly campus climate toward SWDs; regretting a previous disclosure experience including rejections; and lacking the knowledge that nonapparent disabilities may allow them to be eligible for disability support services [19-23].

In a national study of campus disability services, Collins and Mowbray [21] reported that even disability staff were uncertain what kinds of accommodations students with psychiatric (nonapparent) disabilities required and what kinds of accommodations would be reasonable. Much remains unknown regarding students with disabilities and disclosure issues despite the research that supports a positive correlation between students' academic achievement and their usage of student support services, including disability services [1, 19].

\section{METHODS}

The purpose of this pilot study was to examine the characteristics of undergraduates with disabilities at a Western land grant university. Specific attention was paid to identifying nondisclosure/disclosure to disability services; and utilization of accommodations through disability support services.

\section{Participant Recruitment}

Following the University's Institutional Review Board (IRB) approval, an online survey was distributed in 2014 to all undergraduates at a Western land grant university. The survey instrument was comprised of 14 open-ended short answer questions and gathered demographic data such as gender, age, ethnic/cultural background, hours employed while a student, military status, relationship status, college credits completed, academic major, stop out experience (leaving college for one or more semesters), disability identity, whether or not students had formally disclosed their identity to the university's disability services, and whether or not students used any formal accommodation (See Appendix A for Survey Questionnaire). 
At the end of the survey, students had the option to contact the researcher if they were interested in participating in a follow-up face-to-face interview. Fourteen students contacted the researcher to participate in face-to-face interviews and these data will be available in a subsequent publication. This paper presents the survey data.

\section{Participants}

Of the 111 students who completed the online survey, 27.9\% $(n=31)$ indicated that they have or had a disability during enrollment at the university. A total of 80 students did not report having a disability. Of the 31 students with disabilities, $74.1 \%(n=23)$ were women and $25.8 \%$ $(n=8)$ were men. The authors used the terms women and men to denote an accurate representation of gender in this paper, rather than using the terms males and females that refer to sex. The majority of the 31 undergraduate students who reported a disability were Arts and Sciences majors (36.6\%), followed by engineering majors (20\%), business majors $(16.6 \%)$, education majors (13.3\%), and health science majors (10\%). One participant was undeclared. No participant reported having a major in the College of Agriculture.

This study categorized participants into two age groups: 18 to 29 years and 30 years old and older because most undergraduate students fall between the ages of 18 and 29. The majority $(58 \%, n=18)$ of participants with disabilities in this study fell into the age range of 18 to 29 years; $42 \%(n=13)$ were 30 years and older. Non-Hispanic White/European Americans were the largest group of the participants $(87 \%, n=27)$, followed by Latinos $(6.4 \%, n=2)$, Asians (3.2\%, $n=1)$, and African American/Black (3.2\%, n=1). Of the 31 students, $16 \%(n=5)$ identified as veteran students (see Table 1 ).

Table 1

Demographics of Participants Self-Identified as Having a Disability and/or Medical Condition $(N=31)$

$N$

$\begin{array}{lcc}\text { Ages } & & \\ 18-29 & 18 & 58 \% \\ 30 \&> & 13 & 42 \% \\ \text { Gender } & & \\ \text { Men } & 8 & 25.8 \% \\ \text { Women } & 23 & 74.1 \%\end{array}$

$\begin{array}{cll}\text { Race/Ethnicity } & & \\ \text { White } & 27 & 87 \% \\ \text { Latinos } & 2 & 6.4 \% \\ \text { Asians } & 1 & 3.2 \% \\ \text { Black } & 1 & 3.2 \%\end{array}$

$\begin{array}{lll}\text { Military Status } & 5 & 16 \%\end{array}$

Of the 31 students self-identifying with disabilities, the majority reported having nonapparent disabilities (see Table 2). Some students listed having more than one disability, with a range of one to six. There were a total of 24 different types of disabilities listed by these 31students. These are reported in the students' own words. 
Table 2: Disabilities Classifications and Number of Respondents*

\begin{tabular}{|c|c|c|}
\hline Types of Disabilities & Specific Classification & $\begin{array}{c}\text { \# of } \\
\text { Respondents }\end{array}$ \\
\hline \multirow{9}{*}{$\begin{array}{l}\text { Cognitive and learning disabilities, } \\
\text { intellectual disability }\end{array}$} & Dyslexia & 3 \\
\hline & Undisclosed learning disability & 3 \\
\hline & Attention Deficit Hyperactivity Disorder (ADHD) & 1 \\
\hline & Attention Deficit Disorder (ADD) & \\
\hline & Auditory Procession Disorder & 4 \\
\hline & Autism Spectrum Disorder (ASD) & 1 \\
\hline & Traumatic Brain Injury (TBI) & 4 \\
\hline & Epilepsy & 1 \\
\hline & & 1 \\
\hline \multirow[t]{6}{*}{ Psychological or Psychiatric disability } & Post Traumatic Stress Disorder (PTSD) & 4 \\
\hline & Obsessive-Compulsive Disorder (OCD) & 1 \\
\hline & Anxiety Disorder & 4 \\
\hline & Mental Health Disorder & 1 \\
\hline & Depression & 4 \\
\hline & Attempted Suicide & 1 \\
\hline \multirow[t]{3}{*}{ Physical disability } & Paraplegia & 1 \\
\hline & Visual Impairment & 1 \\
\hline & Undisclosed physical disability & 1 \\
\hline \multirow[t]{8}{*}{ Other health impairments (OHI) } & Gall-bladder disease & 1 \\
\hline & Diabetes & 4 \\
\hline & Asthma & 1 \\
\hline & Migraine & 1 \\
\hline & Carpel Tunnel & 1 \\
\hline & Multiple pain conditions & 1 \\
\hline & Cardiac disorder & 1 \\
\hline & Insomnia & 1 \\
\hline
\end{tabular}

$\bar{*}$ Number of disabilities does not add up to 31 because some participants indicated having more than one disability

\section{Data Analysis}

Thirty-one students indicated that they have or had a disability during enrollment at the university. For purposes of the following descriptive data analysis and presentation, one student's information was removed from the data set because the participant did not report disclosing a disability to DSS. Therefore, the following data are based on the data gathered from 30 participants. Also, rather than inferential statics, only descriptive data are presented, given the small sample size in this pilot study and recognition that this small group may not be representative of the larger group of students with disabilities.

\section{RESULTS}

The results of the 30 surveys completed by students who identified as having a disability were analyzed to identify and describe the characteristics of these students. Of the 30 participants, 11 made the decision to disclose their disability to DSS. Analysis was also done to identify and describe the characteristics of students who identify as having a disability but chose not to disclose to DSS $(n=19)$. Data on the use and type of accommodations/services used by the students will also be reported. 


\section{Characteristics of SWDs Who Disclosed and Those Who Did Not}

Of the 30 participants with disabilities, 11 disclosed to DSS (see Table 3) and only eight of those students reported using disability services. Nonetheless, the data indicate that students who disclosed, are likely to use DSS services. Nineteen of the 30 students who reported having a disability did not disclose to DSS. Of this number, fifteen of the 22 women with disabilities did not disclose and four of the eight men did not disclose.

\section{Gender: Disability Status, Disclosure and Service Usage}

A gender analysis of participating students with disabilities was conducted to identify gender similarities and differences regarding disability disclosure and disability services usage.

Women students $(n=22)$ comprised the majority of those who reported having a disability. Of that number of women participants only 7 (32\%) disclosed to DSS. Of interest, however, is that 6 of the $7(86 \%)$ women students who disclosed their disability to DSS, utilized disability services. In contrast, $50 \%(n=4)$ of the men who reported having a disability, disclosed to DSS but only $50 \%(n=2)$ of that number used DSS services.

Table 3: Students Who Reported Disclosing to and Utilizing DSS Services ( $\mathrm{N}=30$ )

\begin{tabular}{|c|c|c|c|c|c|c|c|c|c|c|}
\hline & \multicolumn{2}{|c|}{ Gender } & \multicolumn{2}{|c|}{ Disclosed } & \multicolumn{2}{|c|}{$\begin{array}{l}\text { Did Not } \\
\text { Disclose }\end{array}$} & \multicolumn{2}{|c|}{$\begin{array}{c}\text { Used } \\
\text { Services }\end{array}$} & \multicolumn{2}{|c|}{$\begin{array}{l}\text { Did Not Use } \\
\text { Services }\end{array}$} \\
\hline & W & $\mathrm{M}$ & W & $\mathrm{M}$ & $\mathrm{W}$ & M & W & $\mathrm{M}$ & W & M \\
\hline $\begin{array}{l}\text { Students w/ } \\
\text { disabilities }\end{array}$ & 22 & 8 & 7 & 4 & 15 & 4 & 6 & 2 & 1 & 2 \\
\hline Total & & & & & & & & & & \\
\hline
\end{tabular}

\section{Types of Disabilities, Disability Disclosure and Service Usage}

The majority of students who disclosed and used services were women with cognitive disabilities $(\mathrm{n}=6)$. Also, the three students (one woman and two men) who disclosed but did not follow through with using disability services all had cognitive disabilities. Two of these participants reported having learning disabilities, which they did not name, and the other identified with autistic spectrum disorder (ASD). The students who did not disclose had a range of cognitive, psychological, and physical disabilities, along with a number of other health impairments. It is important to note that some students reported having multiple disabilities (see Table 4).

The large numbers of psychological disabilities reported by students-compared to the small numbers of students with these disabilities who disclosed and used services-warranted closer attention. Six of the nine students who reported having a psychological disability were women. It is interesting to note that the majority of the students with psychological disabilities did not disclose to DSS. Of the nine students who reported having a psychological disability, only one student (woman) disclosed and used DSS services. In general, students with cognitive and learning disabilities were most likely to disclose and use services. On the other hand, students with psychological disabilities were least likely to disclose and use services (see Table 4). 
Table 4: Students, Disability Types, Disclosed and Used DSS Services ( $\mathrm{N}=30)$

\begin{tabular}{lcccc}
\hline & Cognitive \& & \multicolumn{2}{c}{ Types of Disabilities } \\
Learning & Psychological & Physical & $\begin{array}{c}\text { Other Health } \\
\text { Impairments } \\
(\text { OHI })\end{array}$ \\
\hline Not disclosed $(n=19)$ & $8 / 19$ & $12 / 19$ & $2 / 19$ & $10 / 19$ \\
Disclosed $(n=11)$ & $10 / 11$ & $2 / 11$ & $1 / 11$ & $1 / 11$ \\
Used Services $(n=8)$ & $7 / 11$ & $2 / 11$ & $1 / 11$ & $1 / 11$ \\
Did not use services $(n=3)$ & $3 / 11$ & & & \\
\hline
\end{tabular}

Note: Some students listed having more than one disability.

Students reported a range of psychological disabilities, namely: Post Traumatic Stress Disorder (PTSD), Obsessive-Compulsive Disorder (OCD), anxiety disorder, an unnamed mental disorder, and depression (see Table 5).

Table 5: Psychological Disabilities Reported By Students Who Did Not Disclose $(n=12)$

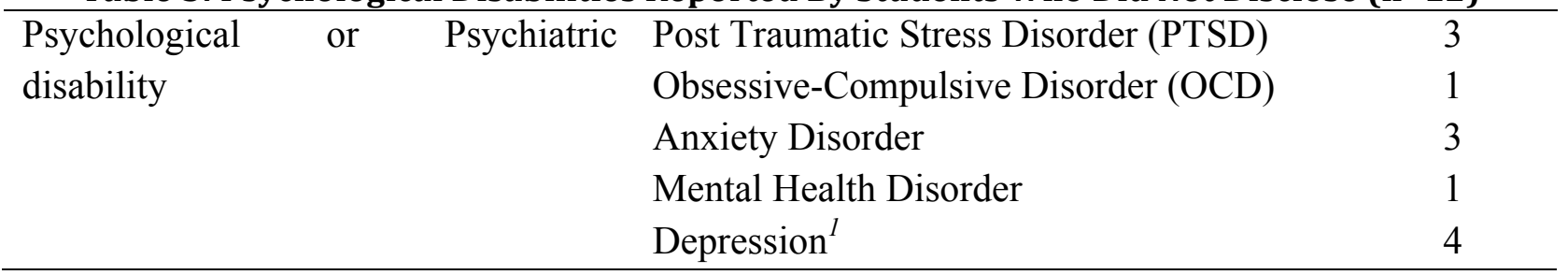

10ne student with depression reported that they attempted suicide.

\section{Employment and Veteran Status}

Of the 11 students who disclosed to DSS, six reported working while enrolled as a student; five students said they did not work while enrolled. Eleven of the 19 students who did not disclose worked during their studies; eight did not. Of the five veteran students who reported having a disability, only one disclosed his disability and also used services. Four of the five veterans who self-identified as having a disability did not disclose the disability to DSS. Whether they disclosed their disabilities to Veteran Services or others in the university is unknown.

\section{Disability Accommodations}

Participating students reported that the most frequent accommodations used were extended test time, test taking at alternative locations, and use of audio books. Other accommodations included the use of a note taker, the ability to audio record all classes, and adaptive adjustment to electronic gadgets. Twenty of the 30 participants who self-identified as having a disability responded to the question as to whether or not they would have benefitted from accommodations; nine said yes, four said no, and five did not know. One student was unaware that DSS could facilitate accommodations; and one had not used services yet.

\section{DISCUSSION}

Building upon research suggesting that utilization of support services and accommodations may improve college outcomes of students with disabilities [1,17], this study aimed to better understand the characteristics of students with self-identified disabilities in relation to disability nondisclosure, disclosure, and utilization of accommodations through DSS. Demographic characteristics were not able to differentiate between those students with disabilities who disclosed to DSS and those who did not disclose. However, the study indicates that the 30 students with disabilities who participated in this survey, are persisting towards completing their degree whether or not they utilize DSS. While persistence was not an explicit 
question in this study, this finding bears similarities to Herbert et al.'s [13] result indicating that SWDs who use disability services persist at similar rates as those who do not and raises questions about the importance of better understanding accommodations. Are accommodations effective for SWDs with regard to persistence, completion rates, or academic success (GPA)? For which disabilities are accommodations most effective? Is there an enduring disconnect between what some students may need: what they actually request or utilize, and what may be available? What is the role of student perceptions in disability disclosure and utilization of DSS? For example, how would SWDs know whether accommodations would or not be of benefit if they have not used them?

It is notable from the survey results that of the 30 students with self-identified disabilities, only 11 disclosed to DSS, and of those, only 8 students, or 26\%, actually utilized services. However, once students decide to disclose to the disability support office, they are highly likely to use accommodations. This study also revealed that most of the students who disclosed and / or used services reported having cognitive and learning disabilities; the types of services students reported using overwhelmingly included test accommodations, extended time, note taking, and accessing class materials in alternative formats. Students with disabilities are likely most familiar with these types of accommodations and may have received them in high school.

As mentioned above, the survey results indicated that the majority of students with psychological or psychiatric disabilities chose not to disclose their disability. This is of particular interest because of the 30 students included in the final analyses, nine reported having a psychological disability (12 different classifications were reported, but some students reported more than one diagnosis). From the group of 30 students, then, $30 \%(n=9)$ selfidentified as having a psychological disability, but from this subgroup of nine students, only one, or $11 \%$, chose to disclose their disability and utilize services. These findings indicate that students with a range of psychological disabilities are persisting with their academic endeavor, even though they do not utilize campus disability support services. Yet, questions remain about why they decide not to disclose, how stigma around mental health issues may impact their support decisions, what other services they may be utilizing, and whether these students fully understand how accommodations could benefit them [13, 17]. Furthermore, accommodations for students with psychological disabilities may not be available.

Providing appropriate supports for students with psychological disabilities is becoming a growing concern among college support service providers [2, 24]. The fact that $30 \%$ of the students in this study identified as having psychological disabilities is in line with national trends in the United States. Recent studies indicate growing numbers of students with psychological disabilities in postsecondary institutions [24, 25] and it will be important to look at how counseling centers, DSS offices, and faculty members can best prepare and support these students' success in the next decades. Stein's [24] research study found that students with psychological disabilities also benefitted greatly from DSS facilitated accommodations common for students with cognitive and learning disabilities such as note taking, extended time on tests, and time management strategies and that these supports were not just "necessary" to their academic success, but having support also made them feel less "alone" and more integrated into the campus community (p. 76).

The fact that only one of the five veterans with disabilities disclosed to DSS and utilize their services may suggest that they receive appropriate services elsewhere, perhaps through the United States Department of Veterans Affairs, but on the other hand, may also indicate that they are not getting any disability services. Also, these veterans with disabilities 
underutilization of campus disability services also support the notion that universities and colleges should consider developing innovative approaches to serve the unique needs of this population and evaluating the effectiveness of disability services [26].

\section{RECOMMENDATIONS}

Given the fact that in this study a little over $63 \%$ of the 30 students who reported having a disability did not disclose, juxtaposed with research studies indicating that disability supports may enhance academic success, it may be important for university and colleges administrators to work with DSS staff to routinely offer disability services accessibility sessions at both new and transfer students' orientation. The findings indicate that students who disclosed were likely to use services supports, thus introducing students to disability services and qualification guidelines during orientation may motivate students to consider formal disability disclosure, eligibility, and service utilization. Finally, special attention should be paid to providing information about resources for students with psychological diagnoses through DSS, counseling centers, and other groups. Targeting all students for disability training, especially focused upon challenging "ableist" misperceptions about disability [27-28], may help to destigmatize disability services and encourage students to seek these services. Alongside the promotion of disability services, future research should also focus on examining the efficacy of disability support services in colleges and universities $[13,23]$.

The needs of veterans may also benefit from special considerations. The reasons that veterans are less likely to disclose and utilize disability services is not clear. A better understanding and collaboration with university veteran services are suggested.

This study indicates that both groups of students, those who disclose and those who choose not to disclose are making progress toward their degree completion. Questions remain regarding factors that may account for this persistence among those students who do not disclose and would be an important area of future research. Further research is also needed to learn more from students about how DSS services may improve their academic success, and on a more far-reaching level, what students would ultimately hope to see in terms of disability access and other DSS offerings. Also, further research is necessary to investigate the knowledge of DSS staff regarding psychological disabilities, eligibility of students with psychological disabilities for disability services and types of accommodations available for these students [24].

Additional research is needed to explore what other formal services SWDs utilize for support and how these services, for example counseling, may mitigate or complement their usage of DSS. Also, given that receiving a diagnosis does not necessarily qualify one for DSS services, further research to examine what conditions students believe qualify for DSS services would be informative for DSS personnel and could help them collaborate with other campus support services to best address the needs of SWDs.

\section{LIMITATIONS}

One of the limitations in this study was that a number of students had multiple disabilities and it cannot be discerned which of the disabilities had the greatest impact on the students' ability to persist, or on their decision to disclose and utilize disability services. Another limitation was that while this study provides insight on disability disclosure and service utilization, the researchers were unable to determine why some students chose not to disclose and seek 
services. Lastly, the findings of this study are limited to the students who completed the survey and may not be applicable to other college SWDs in other geographical locale and context.

\section{CONCLUSION}

The findings of this pilot study suggest that SWDs are persisting with the goal to complete their undergraduate degrees despite the challenges they may encounter along the way. The most notable difference between the characteristics of SWDs who disclosed and those who did not disclose was the prevalence of nondisclosure among students with self-identified psychological disabilities. Otherwise, this survey found no differences in characteristics related to disclosure and nondisclosure. This study also indicates that students were persisting with their education regardless of utilizing disability services, which suggests that SWDs are personally resourceful in ways that could be better understood, and they may have other forms of support systems either on campus or external to the campus.

\section{References}

1. Culligan, M. (2009). Disability and community college retention rates (Doctoral dissertation, Florida State University). Retrieved from http://gradworks.umi.com/33/99/3399186.html

2. Kranke, D., Jackson, S., Taylor, D., Anderson-Fye, E., \& Floersch, J. (2013). College student disclosure of nonapparent disabilities to receive classroom accommodations. Journal of Postsecondary Education and Disability, 26(1), 35-51.

3. Newman, L., Wagner, M., Cameto, R., Knokey, A. M., \& Shaver, D. (2010). Comparisons across time of the outcomes of youth with disabilities up to 4 years after high school: A report of findings from the National Longitudinal Transition Study-2 (NLTS2). Menlo Park, CA: SRI International. Retrieved from www.nlts2.org/reports/2010_09 /nlts2_r eport_2010_09_complete.pdf

4. Wessel, R. D., Jones, J. A., Markle, L., \& Westfall, K. (2009). Retention and graduation of students with disabilities: Facilitating student success. Journal of Postsecondary Education and Disability, 21(3), 116125.

5. National Student Clearinghouse Research Center (July, 2014). Report: Signature Report 7. Retrieved from http://nscresearchcenter.org/signaturereport7/

6. DiRamio, D., Ackerman, R., \& Mitchell, R. (2008). From combat to campus: Voices of student-veterans. NASPA Journal, 45(1), 73-102.

7. Mamiseishvili, K., \& Koch, L. C. (2011). First-to-second-year persistence of students with disabilities in postsecondary institutions in the United States. Rehabilitation Counseling Bulletin, 54(2), 93-105. doi: $10.1177 / 0034355210382580$.

8. Americans with Disabilities Act Amendments (2008). Retrieved from http://www.accessboard.gov/about/laws/ada-amendments.htm

9. Roman, L. G. (2009). Go figure! Public pedagogies, invisible impairments, and the performative paradoxes of visibility as veracity. International Journal of Inclusive Education, 13(7), 677-698.

10. Madaus, J. W. (2011). The history of disability services in higher education. New Directions for Higher Education, 2011(154), 5-15. doi:10.1002/he.429

11. Americans with Disabilities Act of 1990, 42 U.S.C.A. $\S 12101.12102$ et seq

12. Graham-Smith, S., \& Lafayette, S. (2004). Quality disability support for promoting belonging and academic success within the college community. College Student Journal, 38, 90-99.

13. Herbert, J. T., Hong, B. S., Byun, S., Welsh, W., Kurz, C. A., \& Atkinson, H. A. (2014). Persistence and graduation of college students seeking disability support services. The Journal of Rehabilitation, 80(1), 22-32.

14. Orr, A., \& Goodman, N. (2010). People like me don't go to college: The legacy of learning disability. Journal of Ethnographic \& Qualitative Research, 4(4) 213-225. 
15. Thompson-Ebanks, V. (2014). Voluntary withdrawal of college juniors and seniors with nonapparent disabilities: Family, peers, and institutions factors. Journal of Sociology and Social Work, 2(2), 111-134.

16. Wilson, K., Getzel, E., \& Brown, T. (2000). Enhancing the postsecondary campus climate for students with disabilities. Journal of Vocational Rehabilitation, 14(1), 37-50.

17. Troiano, P. F., Liefied, J. A., \& Trachtenberg, J. V. (2010). Academic support and college success for postsecondary students with learning disabilities. Journal of College Reading \& Learning, 40(2), 35-44.

18. Madaus, J., Foley, T., McGuire, J., \& Ruban, L. (2002). Employment self-disclosure of postsecondary graduates with learning disabilities: Rates and rationales. Journal of Learning Disabilities, 35(4), 364-369

19. Hudson, R. L. (2013). The effect of disability disclosure on the graduation rates of college students with disabilities. (Doctoral Dissertation). Retrieved from

http://vtechworks.lib.vt.edu/bitstream/handle/10919/24072/Hudson_RL_D_2013.pdf?sequence=1

20. Barnard-Brak, L., Davis, T., Tate, A., \& Sulak, T. (2009). Attitudes as a predictor of college students requesting accommodations. Journal of Vocational Rehabilitation, 31(3), 189 -198.

21. Collins, M. E., \& Mowbray, C.T. (2005b). Higher education and psychiatric disabilities: National survey of campus disability services. American Journal of Orthopsychiatry, 75(2), 304-315.

22. Lynch, R. T., \& Gussel, L. (1996). Disclosure and self-advocacy regarding disability-related needs: Strategies to maximize integration in postsecondary education. Journal of Counseling and Development: JCD, 74(4), 352.

23. Marshak, L., Van Wieren, T., Ferrell, D. R., Swiss, L., \& Dugan, C. (2010). Exploring barriers to college student use of disability services and accommodations. Journal of Postsecondary Education and Disability, 22(3), 151-165.

24. Stein, K. F. (2015). DSS and accommodations in higher education: Perceptions of students with psychological disabilities. Journal of Postsecondary Education and Disability, 27(2), 60-82.

25. Belch, H. A. (2011). Understanding the experiences of students with psychiatric disabilities: A foundation for creating conditions of support and success. New Directions for Student Services, 134, 73-94.

26. Madaus, J. W., Miller, W. K., \& Vance, M. L. (2009). Veterans with disabilities in postsecondary education. Journal of Postsecondary Education and Disability, 22(1), 14 - 24

27. Linton, S. (1998). Claiming disability: Knowledge and identity. New York, NY: New York University Press.

28. Baglieri, S. \& Shapiro, A. (2012). Disability studies and the inclusive classroom: Critical practices for creating least restrictive attitudes. New York, NY: Routledge.

\section{APPENDIX A: SURVEY QUESTIONNAIRE}

Exploring the experiences of undergraduates with disabilities: Disability disclosure and service utilization

1. What is you age?

2. What is your gender?

3. Which ethnic/cultural background best represents you?

4. During the school year, how many hours do you work on average?

5. Are you a: (a) veteran student (b) military student (c) neither a veteran or military?

6. What semester and year did you begin studying at this university?

7. How may credit hours have you completed?

8. What is your major at this university?

a. What is your minor if applicable?

9. Have you ever stopped attending this university for at least 1 semester? If so, how long did you stop-out?

a. When did you resume your studies?

10. How many semesters have you completed at this university? 
11. Do you have a disability (or had a disability at some point during your studies at this university?

a. If you answered yes to the previous question, what type of disability/ies do you have?

12. Have you disclosed your disability to the disability support services (DSS) on campus?

13. Have you used any accommodations supported by DSS?

a. If, so what type of services do you utilize?

14. Are there any accommodations you would have benefited from that you did not request from an instructor or DSS? 